\title{
UM ENFOQUE DA MORFOLOGIA CONSTRUCIONAL SOBRE AS FORMAÇÕES X-ÁRIO NO PORTUGUÊS ARCAICO
}

\author{
Natival Almeida Simões Neto (PPGLinC/FAPESB/UFBA) \\ Juliana Soledade (UFBA/PROHPOR)
}

\begin{abstract}
RESUMO: Neste artigo, buscamos investigar a polissemia apresentada pelo esquema de construção das formações com o sufixo -ário no português arcaico, para tanto, analisamos um corpus representativo do período em questão (séc. XIII a meados do séc. XVI) e aplicamos a esses dados a proposta de modelo construcional para a morfologia, seguindo Booij (2010, 2012, 2014. Assim, nos dedicamos a apresentar os pressupostos básicos da Morfologia Construcional, entendendo-a como uma alternativa teórico-metodológica para uma Morfologia Histórica, para, então, empreender a análise dos dados, que veio a demonstrar aspectos interessantes acerca das relações polissêmicas entre os tipos de instanciações desse esquema, como, por exemplo, a centralidade da noção relacional ou ainda, as relações metonímicas entre subesquemas agentivos.

PALAVRAS-CHAVE; Morfologia Construcional; Português Arcaico; Polissemia.
\end{abstract}

\section{A FOCUS ON THE CONSTRUCTIONAL MORPHOLOGY FORMATIONS X-ÁRIO IN ARCHAIC PORTUGUESE}

\begin{abstract}
In this article, we investigate the polysemy represented by the formations construction scheme with suffix -ário in Archaic Portuguese, therefore, we analyze a representative corpus of the period (century XIII the middle of the century. XVI) and apply to such data the proposed model for Constructional Morphology, following Booij (2010, 2012, 2014. Thus, we are dedicated to present the basic assumptions of the constructional morphology, understanding it as a theoretical-methodological alternative to a Historical Morphology, to then undertake data analysis, who came to show interesting aspects about the polysemic relations between the types of instantiations of this scheme, for example, the centrality of the relational notion or the metonymic relations between agentive subschemas.

KEYWORDS: Constructional Morphology; Archaic Portuguese; Polysemy.
\end{abstract}

\section{CONSIDERAÇÕES INICIAIS}

O sufixo latino -arius tem, em língua portuguesa, duas formas correspondentes: -ário e -eiro. Estudos de perspectiva histórica, como o de Soledade $(2001,2005)$ e Viaro (2008) mostram que - eiro alcançou uma produtividade que -ário jamais conseguiu. Certamente por isso, há muito mais pesquisas desenvolvidas sobre os aspectos morfossemânticos do -eiro. Neste trabalho, porém, serão tratadas apenas as questões relacionadas à polissemia com as formas em -ário no português arcaico (século XIII ao XVI), sob o enfoque da Morfologia Construcional, como proposta por Booij $(2010,2012,2014)$. 
O modelo proposto por Booij (2010) se alia a algumas agendas da Linguística Cognitiva, não fazendo, por exemplo, clássicas separações como léxico e gramática, conhecimento linguístico e conhecimento enciclopédico e forma e significado. Como observado por Basílio (2010), os estudos desenvolvidos pela Linguística Cognitiva têm se orientado pela constatação de que sintaxe, morfologia e léxico formam um contínuo de unidades simbólicas que materializam processos cognitivos capazes de evocar a relação entre o homem e a realidade. As palavras, então, não devem ser observadas somente em seus aspectos formais, representados por regras de formação, precisando considerar também as redes de significado que são ativadas conforme o uso.

A associatividade entre forma, função e significado é prevista no modelo da Morfologia Construcional. Se na Hipótese Lexicalista do Gerativismo, a competência lexical do falante lhe permitia, a partir de um conjunto restrito de palavras, depreender os aspectos formais de regras de estruturação das palavras, que servirão de base para a formação de novas palavras, no âmbito da Morfologia Construcional, o falante exposto a um conjunto de palavras complexas compreende os esquemas construcionais atuantes, que envolvem tanto os aspectos formais quanto os semântico-funcionais e, por meio deles, prevê o significado de outras palavras formadas pelo mesmo esquema e cunha novas a partir deles.

Esses esquemas morfológicos, segundo Booij (2010, 2014), não devem ser entendidos como mecanismos formais para representações lexicais econômicas, como acontece nos modelos de Jackendoff (1975) e de Aronoff (1976). A principal função dos esquemas é motivar a existência de um conjunto de palavras complexas, prevendo como se dá a sua extensão e reduzindo o nível de arbitrariedade das relações de forma-significado nessas palavras. Além disso, os esquemas morfológicos contribuem para a estruturação do léxico, no momento em que esquemas construcionais como $\mathrm{X}$-ário revelam parte da estrutura do léxico dos falantes de língua portuguesa.

As palavras formadas pelo esquema são, segundo Booij (2010), suas instanciações. Assim, abecedário é entendida como uma instanciação do esquema morfológico $X$-ário. Para formar novas palavras em -ário, deve haver uma substituição da parte variável do esquema (o X que representa o input), resultando, nos termos de Booij (2010), em uma operação de unificação entre o item lexical e o esquema $\left[\mathrm{X}_{\mathrm{i}} \text {-ário }\right]_{\mathrm{Nj}}$. Gonçalves e Almeida (2013), leitores de Booij (2010), preferem, no entanto, usar o termo compatibilização, pois entendem que deve haver uma combinação das propriedades do item lexical com as propriedades semânticas dis- 
ponibilizadas pelo esquema. Isso pode ser visto em criações do século XX (cf. Houaiss e Villar, 2001), como fraldário (lugar público em que se faz troca de fralda), berçário (lugar em que ficam os berços) e rimário (coletânea de rimas). As propriedades semânticas de rima se diferem das de fralda e berço, o que faz com que rimário não seja, a priori, instanciada por um esquema de lugar.

A polissemia, advinda de metáfora, metonímia ou de outros processos, pode atuar em um conjunto particular de palavras disponibilizadas por um mesmo esquema dominante, orientando para um novo significado que deverá ser representado por meio de subesquemas, que partirão dos diferentes níveis de generalizações e graus de abstração. Em se tratando dos exemplos mencionados do sufixo -ário, por exemplo, a polissemia pode atuar em um esquema dominante como o de lugar, criando distinções entre lugar onde há grande quantidade de $X$ (berçário) e lugar onde se faz algo relacionado a X (fraldário). Essas distinções, então, devem ser especificadas em subesquemas. A relação entre esquemas e subesquemas é uma das representações da visão hierárquica e radial do léxico, defendida por Booij (2010).

Com base nesses pressupostos, o artigo que aqui se desenvolve segue os passos de Soledade (2013), ao apresentar a Morfologia Construcional como uma alternativa teóricometodológica para uma Morfologia Histórica. Feitas as considerações iniciais na seção 1, a seção 2 detalhará mais propriedades do modelo a ser seguido. A seção 3 revisará os trabalhos desenvolvidos sobre o -ário. Na seção 4, apresentar-se-á o corpus de análise e aplicar-se-á sobre ele o modelo de Booij (2010). Na seção 5, serão feitas as considerações finais, seguidas das referências.

\section{ESQUEMAS CONSTRUCIONAIS: APRESENTANDO PROPRIEDADES E LANÇANDO QUESTÕES}

O esquema construcional, conceito de suma importância para a teoria desenvolvida por Booij (2010), tem uma representação formal própria. Soledade (2013, p. 87), leitora de Booij (2012, p. 04), explica que devem ser representados da seguinte maneira:

(01) $<\left[\mathrm{X}_{\mathrm{i}} \mathrm{Y}\right]_{\mathrm{Yk}} \leftrightarrow\left[\text { significado de } \mathrm{Y} \text { relacionado a } \mathrm{SEM}_{\mathrm{Xi}}\right]_{\mathrm{k}}>$

Soledade (2013), seguindo Booij (2012), explica que, nessa representação, os símbolos de maior que e menor que demarcam o esquema e o símbolo $(\leftrightarrow)$ relaciona forma e significa- 
do no interior do esquema. Essa relação se torna evidente também através da coindexação do significado da palavra base, à direita da seta, à parte relevante da estrutura formal do lado esquerdo da seta. "O significado (SEM) das palavras da base só é especificado no léxico, ao passo que a contribuição do significado fornecida pelos afixos é especificada nos esquemas de construção" (SOLEDADE, 2013, p. 87), pois seus significados não são autônomos em relação à estrutura morfológica em que ocorrem.

Como o modelo construcional se volta para a palavra e não para o morfema, Booij (2010) entende que cada item lexical apresenta um pareamento de características fonológicas (PHON), morfossintáticas (SYN) e semânticas (SEM). Nesses moldes, o autor considera que, para a formulação de esquemas, existam características absolutas e anuláveis, que são detalhadas a seguir.

\subsection{CATEGORIA DO INPUT E CATEGORIA DO OUTPUT}

A primeira característica que Booij $(2010,2014)$ considera imprescindível diz respeito às categorias do input (palavra primitiva; base) e do output (palavra complexa; produto). $\mathrm{O}$ autor propõe que, nos esquemas, só uma dessas categorias seja fixa: a categoria morfossintática do output. Nesse contexto, Booij $(2010,2014)$ se mantém fiel à hipótese gerativista do Produto Categorial Único, de Aronoff (1976). Na visão de Aronoff, toda palavra derivada deve fazer parte de uma categoria lexical exata, especificada pela regra de formação da qual se originou. Nos termos construcionais, a categoria lexical exata da palavra complexa (output) deve ser especificada pelo esquema construcional do qual ele é uma instanciação e herda suas propriedades. Booij $(2010,2014)$ mostra que há alguns esquemas em que a categoria da palavra base pode ser anulada, e outros que parecem ser mais rígidos quanto à especificidade categorial da base. Em português, as construções $X$-ção e X-mento têm sempre verbos como inputs e substantivos como outputs. Por isso, nesse caso, não é permitido que os esquemas sejam indiferentes nem à categoria morfossintática do input, nem à do output. As construções em -ismo, por outro lado, possibilitam essa anulação, como mostrado por Soledade (2013, p. 88): 
(02)

$\begin{array}{ll}\text { Base } & \text { Raiz } \\ \text { Sc } & \text { átomo, derrota } \\ \text { Sp } & \text { Lula, Carlos (ACM) } \\ \text { A } & \text { colonial, favorito } \\ \text { V } & \text { batizar, caquizar, } \\ \text { C } & \text { bota-abaixo, sem-vergonha } \\ \text { Sig } & \text { PT, PMDB }\end{array}$

\author{
Substantivo derivado \\ atomismo, derrotismo \\ lulismo, carlismo \\ colonialismo, favoritismo \\ batismo, catecismo \\ bota-abaixismo, sem-vergonhismo \\ petismo, peemedebismo
}

Soledade (2013) observa que, mesmo a formação a partir de bases adjetivas (A) sendo a mais produtiva na história da língua portuguesa, a forma etimológica grega -ismós tinha por base verbos, mas essas formações não têm expressividade em termos de produção no português contemporâneo, contexto em que se verifica o surgimento de novas possibilidades bastante produtivas, como a seleção de bases das categorias dos substantivos próprios (Sp) e das siglas (Sig). Tudo isso sugere que, no esquema dominante de -ismo, a categoria da base não é uma propriedade absoluta, sendo possível essa informação ser omitida. No entanto, deve-se especificá-la por meio de subesquemas, quando for uma característica relevante e produtiva. Soledade (2013, p. 88), sugere, portanto, que o -ismo apresente um esquema dominante como em (03):

$$
<\left[\mathrm{X}_{\mathrm{i}}-\mathrm{ismo}\right]_{\mathrm{Sj}} \leftrightarrow[\text { relacionado a SEMi }]_{\mathrm{Sj}}>(\text { SOLEDADE, 2013) }
$$

Sobre essa formulação em (03), Soledade (2013) observa que a categoria do constructo, ou seja, do conjunto de palavras que foi e pode ser gerado
por um esquema, parece ser uma propriedade essencial, haja vista, no caso das pala-
vras formadas por esquemas de sufixação, a sua função essencial de determinar a ca-
tegoria morfossintática do item lexical gerado (SOLEDADE, 2013, p. 88).

A respeito da manutenção da proposta de Aronoff do Produto Categorial Único, elaborada numa perspectiva gerativista, cabe mencionar outras formas de tratamento dessa questão. A primeira foi feita inicialmente por Basílio (1980) e aprimorada em Basílio (1981 apud MARINHO, 2004), ainda no âmbito gerativo, embora também semântico-associativo. A segunda proposta foi vista em Botelho (2009), dentro de um modelo sociocognitivista em que se intenta aplicar a Gramática das Construções, proposta por Adele Goldberg, aos vários tipos de construções da língua portuguesa, incluindo a morfologia.

No entendimento de Basílio (1980), a aplicação do Produto Categorial Único pode ser problemática para alguns casos. Em português, a autora (1980, p. 90) observa isso com o su- 
fixo - dor, assumindo que a regra de formação prevista para o sufixo seja como expressa em (04):

(04) $[\mathrm{X}]_{\mathrm{V}} \rightarrow\left[[\mathrm{X}]_{\mathrm{V}} \text { dor }\right]_{\mathrm{N} \text { Ag }}($ BASÍLIO, 1980)

A formulação em (04) propõe que o sufixo - dor opera sempre sobre bases verbais (V) e tem sempre como produto um substantivo (N) com valor agentivo (Ag). Basílio (1980), no entanto, chama a atenção para o fato de que essa regra só dá conta de uma parte do conjunto de palavras possíveis formadas pelo referido sufixo agentivo. A autora apresenta exemplos:

(05) (a) O administrador não conseguiu resolver o problema (BASÍLIO, 1980).

(b) A firma administradora não conseguiu resolver o problema (BASÍLIO, 1980).

Com essas sentenças, Basílio (1980) sugere que alguns agentivos em - dor podem flutuar entre as categorias de adjetivos e substantivos. Outros exemplos dados por ela são produtor (o produtor, a firma produtora), gerador (o gerador, mecanismo gerador), colonizador (o colonizador, os grupos colonizadores). Há também a constatação de que alguns agentivos que aparecem somente como substantivos e outros que aparecem somente como adjetivos. Os exemplos em (06) mostram os agentivos que são apenas substantivos e (07) exibe aqueles que são somente adjetivos, nos termos de Basílio (1980).

(06) governador - cobrador - escultor - maquilador — ventilador (BASÍLIO, 1980)

(07) tentador - revelador - desesperador - promissor - enganador (BASÍLIO, 1980)

Diante de todas essas constatações, Basílio (1980) observa que: (i) os agentivos em dor são formados por uma mesma sequência fonológica e com o mesmo significado geral de “que X”, em que X expressa o significado da base; (ii) as bases selecionadas pelo sufixo são sempre verbos; e (iii) "a determinação das possíveis interpretações de agentivo X-dor está diretamente relacionada à presença de traços +N e +Adj” (BASÍLIO, 1980, p. 93). A autora conclui que, com base nas descrições feitas, o sufixo - dor deve apresentar duas regras de produção, caso seja seguida a proposta de Aronoff : uma seria a expressa em (04) e a outra está expressa em (08).

(08) $\quad[X]_{\mathrm{V}} \rightarrow\left[[\mathrm{X}]_{\mathrm{V}} \text { dor }\right]_{\mathrm{Adj} \text { Ag }}($ BASÍLIO, 1980)

A única diferença entre (04) e (08) é, portanto, a categoria do produto. Representar as duas dessa forma é admitir que uma mesma sequência fonológica correspondente a um item lexical seja duplicada no léxico. Ou seja, haveria, por exemplo, duas entradas para a palavra 
administrador, uma substantiva e outra adjetiva. Nesses casos de agentivos flutuantes, Basílio (1980) propõe algo como (09):

(09) $[\mathrm{X}]_{\mathrm{V}} \rightarrow\left[[\mathrm{X}]_{\mathrm{V}} \text { dor }\right]_{\mathrm{R}}$ em que R é uma arquicategoria (BASÍLIO, 1980)

Basílio (1981, apud Marinho, 2004) observa que o mesmo tipo de flutuação categorial que ocorre com o sufixo - dor acontece com o sufixo - nte e sugere que essa seja uma característica dos agentivos deverbais, ratificando que, para esses casos, haja uma regra de formação única e de produto arquicategorial, como em (9). Nesse trabalho de 1981, a autora propõe que as operações lexicais sejam abordadas por dois níveis. No primeiro, está o nível da formação de palavras, onde estão inseridas as regras de formação. No segundo nível, Marinho (2004, p. 28) interpreta que estão as "variações no sentido da palavra e a possibilidade de emprego do vocábulo com mais de uma especificação categorial”. Assim, para Basílio (1981), a atribuição categorial não deve aparecer nas regras de formação, pois não é uma informação da morfologia, e sim da sintaxe. A partir disso, a autora propõe, para além da regra de formação, uma regra de extensão de categoria, que atua no componente sintático.

Em um modelo como o gerativista, de caráter modular, essa proposta de Basílio (1981) de extensão de categoria se mostra eficiente para o tratamento da flutuação categorial de agentivos.

Outros autores, como Marinho (2004) e Souza (2006), aplicaram as propostas de Basílio sobre derivações do tipo $X$-eiro e $X$-ário, que tomam prototipicamente bases substantivas, e encontraram correspondência, o que sugere que esse fenômeno seja característico dos agentivos de uma forma geral.

A flutuação categorial é um fenômeno aparentemente restrito a substantivos e adjetivos, revelando-se como um problema histórico na descrição das línguas. A dificuldade de definir quais os limites dessa ou daquela categoria existe desde a tradição greco-latina, como observam Lobato (1986) e Castilho (2010). Os estudiosos da Antiguidade Clássica não distinguiam as duas classes e consideravam uma categoria maior nomen (nome) ${ }^{1}$, com especificações de nomen substantiuum (nome substantivo) e nomen adiectuum (nome adjetivo). Somente no século XVIII, segundo Castilho (2010), os estudiosos das línguas românicas passaram a dis-

\footnotetext{
Sobre isso, cabe menção ao trabalho de Perini (1995) em que o autor se questiona se há mesmo a necessidade de serem definidas duas categorias, considerando que as propriedades morfossintáticas e semânticas de substantivos e adjetivos são muito próximas. Sobre o assunto da flutuação categorial, são destacáveis os trabalhos de Câmara Jr. (1970), Basílio (1995) e Viaro (2006).
} 
tinguir as duas categorias. Justamente nessas línguas, observa-se esse fenômeno em maior produtividade.

A importância de trazer aqui a proposta de Basílio $(1980,1981)$ é questionar se a categoria do output não é, até certo ponto, anulável, quando a extensão categorial é muito produtiva no sistema linguístico em uso. Se Basílio (1980, 1981), ainda inserida num modelo gerativista, foi capaz de modalizar a proposta de Aronoff (1976), talvez seja o caso de o modelo proposto por Booij ver se é realmente interessante para a descrição linguística considerar esquemas particulares para instanciações em que a flutuação é previsível, como nos contextos de agentivos que ora se realizam como substantivos, ora como adjetivos.

Botelho (2009) trabalha com as construções X-eiro no português brasileiro contemporâneo, tentando aplicar sobre essas os pressupostos da Gramática das Construções e experimentando uma perspectiva cognitivista e construcional sobre a morfologia. Essa abordagem, no entanto, não se vincula às propostas de Booij, embora esse também parta das reflexões de Goldberg. Ao abordar as palavras derivadas em - eiro, Botelho (2009) não distingue as categorias de adjetivos e substantivos, no que tange à noção de agentividade, propondo que essa distinção seja proveniente de uma projeção semântico-pragmática de figura-fundo. Esse mecanismo, segundo Valenzuela, Ibarretxe-Antuñano e Hilferty (2012), é um conceito gestaltista que aparece de maneira basilar nos pressupostos da Linguística Cognitiva e através dele, focaliza-se, de maneira preferencial, a atenção para uma zona concreta do domínio, destacando-a de todo o resto. Nesses termos, o elemento destacado é figura e todo o restante é fundo. Em se tratando de morfologia, mais precisamente das construções agentivas X-eiro, Botelho (2009) sugere que os usos substantivos tornam figura a agentividade no elemento derivado, ao passo que os adjetivos a colocam como fundo. Exemplos da autora estão em (10).

(10) (a) O traiçoeiro chegou ... vamos ficar quietos! (BOTELHO, 2009)

(b) Ele teve uma atitude traiçoeira e perdeu a confiança de todos (BOTELHO, 2009)

No entendimento de Botelho (2009), (10a) apresenta traiçoeiro como um substantivo e (10b) mostra traiçoeira como um adjetivo. Nesses casos, a noção agentiva de aquele que comete traição perpassa as duas realizações, mas em (10a), a agentividade é central (figura), pois, metonimicamente, designa-se o agente pelo ato que comete (cf. BASÍLIO, 2011) e em (10b), a agentividade é periférica (fundo), pois qualifica a atitude tomada por um agente. 
Com base nessas constatações, sugere-se que um esquema para agentivos em -dor, em um modelo construcional como o booijiano, possa ser representado como em (10), em que R é a arquicategoria que engloba substantivos e adjetivos, tal qual sugerido por Basílio (1980).

(11) $<\left[\mathrm{X}_{\mathrm{Vi}}-\text { dor }\right]_{\mathrm{Rj}} \leftrightarrow\left[\text { AGENTE envolvido em } \mathrm{SEM}_{\mathrm{Vi}}\right]_{\mathrm{Rj}}>^{2}$

Em que se pese a recorrente e inacabada distinção entre categoria e função nos estudos linguísticos e eximindo-se de chegar a uma proposta definitiva acerca da flutuação categorial histórica entre substantivos e adjetivos, a representação em (11) ainda precisa de maiores debates. Entretanto, para uma descrição morfológica em um modelo sistemicamente conectado, como o da Linguística Cognitiva e da Morfologia Construcional, talvez seja interessante discutir se a categoria dos constructos não deve ser atribuída de maneira mais integradora, promovendo uma interface entre morfologia, sintaxe e semântica, e desfazendo-se da proposta de que deva ser uma tarefa somente do léxico, como cunhado por Aronoff (1976) e mantido por Booij (2010). Assumir uma proposta dessa natureza no modelo construcional, entretanto, incorre no risco de só restarem fonologia e semântica para atribuírem a categoria dos constructos, desprivilegiando talvez o papel da morfologia.

\subsection{HERANÇA DO CORPO FÔNICO NAS CONSTRUÇÕES}

A segunda característica que Booij $(2010,2014)$ considera absoluta em um esquema é a herança do corpo fônico das construções, mas não deixando de considerar o fenômeno da alomorfia, alteração na representação fonológica dos morfemas, e o seu impacto para a formulação dos esquemas. Em Booij (2014, p. 24), o autor apresenta dois exemplos em que discute o fenômeno, com base em palavras do holandês e do italiano, adaptados e traduzidos respectivamente em (12) e (13).

2 A formulação desse esquema pode ser comparada à formulação da regra de formação do modelo gerativista de Aronoff, apresentada em (09). Uma das diferenças significativas entre esquema e regra é a possibilidade de o input variar de categoria no esquema. Embora, nesse exemplo de -dor não varie, no modelo construcional, isso pode acontecer, como visto no exemplo com -ismo, enquanto no modelo gerativista, diferenças entre as categorias dos inputs requerem postulações de regras distintas. Segundo Booij (2010), isso se deve, sobretudo, ao fato de a teoria de Aronoff ser pautada no input e nas relações que estabelecem com as operações morfológicas que atuam sobre ele, ao passo que a teoria construcional se volta mais focadamente para o output, ainda que não desconsidere as questões ligadas à base. A diferença mais impactante, no entanto, é a explicitação da contraparte semântica que não acontece nas regras de formação gerativistas. $\mathrm{O}$ modelo construcional, portanto, considera, em primazia, o significado das construções, sem deixar de levar em conta os seus aspectos formais. 
(12) (a) aanva[y] 'begin' (início) aanva[nk]-elijk 'initially' (inicialmente)

(b) toega[y] 'access' (acesso) toega[ $\mathrm{nk}]$-elijk 'accessible' (acessivel)

(c) afha[y] 'to depend' (depender) afha[nk]-elijk 'dependent' (dependente)

(13) (a) ami[k]-o — ami[tš $]-\mathrm{i}$ 'friend(s)' (amigo)

ami[tš]-izia 'friendship' (amizade)

(b) mendi[k]-o - mendi[k]-i 'mendicant(s)' (mendigo) mendi[tš]-izia 'mendicity' (mendicidade)

Em (12), Booij (2014) mostra derivações com o sufixo holandês -elijk. Nos três casos, há uma mesma variação no corpo fônico da base, portanto uma alomorfia regular: todas as bases terminam com o fonema [y] e, quando derivadas com - elijk, o fonema [k] se agrega à base. Essa alteração, no entanto, não impede que relações lexicais entre input e output sejam estabelecidas. O mesmo pode ser dito de (13), com as palavras derivadas com o sufixo italiano -izia: as bases sofrem uma alteração previsível no seu corpo fônico, com o fonema [k] passando a [tš], sem prejudicar as relações. Alguns exemplos do português podem ser vistos em (14) e (15).

(14) (a) coleção - colecionar

(b) infecção - infeccionar

(c) seleção - selecionar

(15) (a) árvore - arbóreo

(b) lágrima - lacrimal

(c) vidro - vitral

Os exemplos em (14) mostram a derivação de verbos cujas bases têm o sufixo -ção, oriundo do latim -ť̌on, ōnis. Nesses casos, há uma tendência de as bases retomarem, em parte, sua forma etimológica na formação dos verbos. Em (14a), colecionar deriva de coleção, cujo étimo é o latim collectı̆o, onis. A base colecion, então, remete à forma latina. (14b), com infeccionar, e (14c), com selecionar, seguem o mesmo modelo, com o primeiro vindo de infecção (infēctǐo,ōnis) e o segundo de seleção (selectĭo, ōnis). Essas pequenas alterações não impedem as relações lexicais de se estabelecerem.

Nos casos em (15), as alomorfias das bases também remetem aos étimos das palavras, que são retomados nas palavras derivadas: árvore vem do latim arbor, -ŏris, lágrima vem do latim lacrima, -ae e vidro vem do latim vitrum, -ī. Essas situações, portanto, confirmam: (i) o caráter histórico de alguns fenômenos de alomorfia; (ii) a necessidade da investigação histórica da morfologia, como sugerem Soledade (2005), Viaro (2010) e Lopes (2013); e (iii) a im- 
portância de o modelo linguístico se permitir a integrações elegantes com os achados de outras disciplinas, como, por exemplo, a Linguística Histórica, conforme as sugestões de Jackendoff (2011, apud BOOIJ, 2014).

Para esses casos de alomorfia, Booij (2014), então, assume que a herança completa do corpo fonológico não é imprescindível para o reconhecimento de uma relação lexical e admite que o corpo fonológico seja, até certo ponto, uma categoria anulável, se as relações semânticas envolvidas estiverem suficientemente claras. Nota-se, nessa proposta de Booij (2014), a omissão de contextos em que a alomorfia impede as relações lexicais entre input e output. Sugestões para isso estão expressas em (16):

(16) (a) chuva - pluvial

(b) ilha - insular

(c) peixe - písceo

Em (16), há, respectivamente, exemplos com os sufixos -al,-ar e -eo. Todas as palavras são instanciações de esquemas construcionais que têm como outputs adjetivos de valor relacional e selecionam como input um substantivo. Embora apresentem significados similares, trata-se de formas fonológicas distintas, reivindicando, por isso, esquemas construcionais diferentes. Observa-se que há, nesses casos, necessidade de um conhecimento histórico da língua, pois o estabelecimento das relações lexicais parece ser menos visível nesses casos. Esquemas hipotéticos são apresentados para os exemplos de (16) estão formulados em (17).

(17) (a) pluvial: $<\left[\left[\text { chuva }_{\mathrm{Si}}\right] \text { al }\right]_{\mathrm{A}} \leftrightarrow\left[\text { QUALIDADE RELATIVA a } \mathrm{SEM}_{\mathrm{Si}}\right]_{\mathrm{A}}>$

(b) insular: $<\left[\left[\text { ilha }_{\mathrm{Si}}\right] \text { ar }\right]_{\mathrm{A}} \leftrightarrow\left[\text { QUALIDADE RELATIVA a } \mathrm{SEM}_{\mathrm{Si}}\right]_{\mathrm{A}}>$

(c) písceo: $<\left[\left[\text { peixe }_{\mathrm{Si}}\right] \text { eo }\right]_{\mathrm{A}} \leftrightarrow$ [QUALIDADE RELATIVA a SEM $\left.\mathrm{Si}_{\mathrm{A}}\right]_{\mathrm{A}}$

Nota-se em (17) que as formas derivadas remetem ao étimo dos inputs. Em (17a), pluvial retoma o latim plŭvia, -ae (étimo de chuva), da mesma forma que, em (17b), insular remete ao latim insŭla, -ae (étimo de ilha). Em (17c), písceo se aproxima de piscis, -is (étimo de peixe). Se comparados aos casos em (15), os exemplos em (17) apresentam bases que, ao longo da história da língua, sofreram transformações fonológicas mais impactantes, sendo esse talvez um contexto em que o estabelecimento de relações lexicais entre input e output seja mais difícil. Nesses casos, lançam-se duas hipóteses: (i) os itens lexicais derivados de (16) devem ser considerados instanciações dos esquemas em (17) e a herança do corpo fônico passa a ser uma propriedade anulável, nos termos de Booij (2010, 2014); ou (ii) os itens derivados em (16) devem ser assumidos como convencionalizados ou idiossincráticos, cabendo um 
armazenamento no léxico como itens lexicais desvencilhados de esquemas morfológicos como os de (17).

Outra ausência na proposta de Booij (2014) é a discussão se essa alomorfia, sempre exemplificada com os inputs, pode se estender aos afixos. Ou seja, é possível que, para sufixos ditos alomorfes, o corpo fonológico seja também anulável, até certo ponto? Sejam observados os casos em (18).

(18) (a) medidor - auditor - professor

(b) duradouro - classificatório

Em (18a), há exemplos de derivados dos sufixos alomorfes -dor, -tor e -sor, todos provenientes do latim -or,-oris. As três palavras podem ser consideradas instanciações de um esquema como em (11). O mesmo não pode ser dito dos casos em (18b). Tanto o sufixo douro quanto o -tório são oriundos do latim -orius, $-a$, $-u m$, mas um falante comum, talvez não faça essa associação com a mesma rapidez que faz nos casos em (18a). Nesses casos, por -douro e-tório apresentarem formas fonológicas tão distintas, não se pode aceitar que, embora adjetivos, duradouro e classificatório sejam considerados instanciações de um mesmo esquema, requerendo, assim, dois esquemas distintos para as suas representações.

Cumpre ressaltar ainda em relação a (18a) que esses exemplos encontram correspondência no tratamento proposto por Basílio (1980) para o sufixo -dor. A autora é indiferente à alomorfia sufixal nesse caso. Dessa forma, a ideia de Booij (2014) de que a conservação do corpo fônico é uma propriedade que pode ser anulada em alguns contextos de alomorfia da base pode ser estendida para alguns contextos dos afixos, desde que se mantenha a ressalva de que essa alteração fonológica não deve impedir a identificação de relações lexicais. Assim, no que toca aos sufixos, se for possível estabelecer relações entre os alomorfes, como é possível, com -dor e os seus, não há motivos para não estender a visão de Booij (2014). Se num modelo formalista, como o empenhado por Basílio (1980), há essa aceitabilidade, não há porque um modelo mais associativo não aceitar, com cautela, a alomorfia de sufixos.

\subsection{AS PROPRIEDADES SEMÂNTICAS NOS ESQUEMAS}

Na formulação dos esquemas, a terceira e última característica que Booij (2010) estabelece como imprescindível são as propriedades semânticas das construções, pois essas são tidas 
como centrais no processo de organização do sistema cognitivo, não permitindo que o esquema as dispense. Entretanto, nem sempre essas são passíveis de uma descrição em termos de substituição de variáveis. Soledade (2013) observa que

Há casos em que as propriedades semânticas das palavras complexas individuais não estão previstas pelo esquema morfológico dominante. Esse fato decorre de que muitas vezes atuam sobre itens lexicais complexos mecanismos universais de polissemia, decorrentes de extensões metonímicas e metafóricas. Assim, uma palavra complexa pode ter propriedades semânticas que não são motivadas pelo esquema morfológico dominante (SOLEDADE, 2013, p. 89).

Segundo Booij (2010), as palavras morfologicamente complexas nem sempre podem ser analisadas em termos componenciais, pois, não raras vezes, são carregadas de significados específicos (metafóricos, sobretudo) que não são derivados dos significados dos elementos constituintes. Embora destaque a centralidade do componente semântico para um modelo construcional aplicado à morfologia, é tímida a incursão de Booij sobre as questões que implicam uma reflexão acerca dos sentidos e das relações que estes estabelecem entre si.

Assim, o modelo com base no desenvolvimento de rede construcional morfológica, nos moldes de Goldberg (1995), oferece fundamentos essenciais para a compreensão da estruturação do léxico em termos de construção e esquemas; contudo, ainda não é suficiente para dar conta de aspectos importantes, sobretudo, quando se trata da contraparte semântica e das mais variadas relações de sentido que demandam especificação.

\section{CONSIDERAÇÕES SOBRE O MORFEMA - ÁRIO}

O produtivo sufixo latino - arius chegou à língua portuguesa sob duas formas: os sufixos -ário e -eiro. Se tomada a abordagem estruturalista de Câmara Jr. (1970, 1975) e Elson e Picket (1973), -ário e -eiro seriam tratados como alomorfes, pois provêm de um mesmo étimo, às vezes apresentam o mesmo valor linguístico e estão em contextos de distribuição complementar, ou seja, em um contexto morfológico em que um se realiza, o outro tende a não se realizar. Soledade $(2001,2005)$ e Viaro (2008), com abordagens historicistas, sugerem que sejam considerados morfemas divergentes, pois, embora de uma mesma origem etimológica, os dois morfemas seguiram trajetórias distintas. Uma terceira proposta para tratar os dois elementos é seguir a proposta de Rio-Torto (2014) e considerá-los morfemas cognatos que se diferenciam pelo grau de erudição das suas formações, em que o -ário seria [+ erudito] e o - 
eiro [- erudito]. Os segundo e terceiro termos se mostram mais pertinentes, por razões que ficarão mais claras a partir da seção 4 .

Com base nas constatações de de Soledade $(2001,2005)$ e Viaro (2008) a respeito de o -eiro ter alcançado uma produtividade que -ário jamais conseguiu, é possível justificar o porquê de os estudos sobre -ário se mostrarem bem menos recorrentes. A título de revisão, sobre o morfema -ário, foram considerados aqui: (i) os trabalhos descritivos das gramáticas históricas de Said Ali (1964) e Nunes (1969); (ii) a descrição feita por Soledade (2001, 2005), dentro de um quadro panorâmico de sufixação nominal do português arcaico; (iii) o trabalho diacrônico de orientação gerativista feito por Souza (2006); e (iv) o trabalho diacrônico semânticoevolutivo empreendido por Viaro (2008).

\subsection{O QUE DIZEM AS GRAMÁTICAS HISTÓRICAS?}

Algumas gramáticas históricas, como as de Said Ali (1964) e Nunes (1969), deram contribuições significativas para o estudo histórico da morfologia, fornecendo informações sobre o funcionamento de afixos portugueses, desde a sua forma etimológica até o estado atual naquele contexto.

A respeito do -ário, tanto Said Ali (1964) quanto Nunes (1969) apresentam o morfema de maneira secundária em relação ao seu divergente -eiro. Em Gramática Histórica da Língua Portuguesa, Said Ali (1964) observa que, a partir de -arius, a trajetória do sufixo foi ariu $>$ airo > eiro, em que -airo é uma forma intermediária atestada no período arcaico e que, em função do caráter erudito dos latinismos, tendeu a retomar forma -ário. A influência da erudição latinista é destacada pelo autor, em formações do português que retomam a norma latina, como argentário, funcionário e fracionário. São mencionados também os paralelismos de formas de mesma etimologia, como operário e obreiro, ovário e oveiro e solitário e solteiro. O último destaque dado nessa gramática é a formação de adjetivos, que o autor considera produtiva, exemplificando com originário, plenário, precário e subsidiário. Na descrição de Said Ali (1964), não há qualquer tratamento semântico sobre o -ário, ao passo que o -eiro é mais detalhado.

Em Compêndio de Gramática Histórica Portuguesa, Nunes (1969) aborda o -ário também de maneira secundária, em relação a -eiro e - deiro. $\mathrm{O}$ autor observa que os sufixos ori- 
ginados do latim - ariu veiculam acepções, como profissão, instrumento, lugar e aglomeração. Ao apresentar os exemplos, o autor divide em dois grupos: um para formações em -eiro e deiro e outro para as formações em -ário. No primeiro grupo, há ainda três subgrupos: um para as formações em - eiro, sem diferenciações semânticas, o segundo para as formações em - deiro, sem detalhamentos também, e o terceiro para as formações em -eiro de agentes vegetais (figueira, amendoeira). No grupo de -ário, não há tratamentos semânticos, mencionandose apenas exemplos como vigário, armário, depositário, boticário, corsário, relicário e sagitário.

\subsection{O SUFIXO NO QUADRO GERAL DO PORTUGUÊS ARCAICO}

Em seus trabalhos sobre a sufixação nominal no português arcaico, Soledade (2001, 2005) observa uma menor produtividade do -ário em relação ao -eiro, mas alertando que esse não caiu em desuso e, no português contemporâneo, foram criadas novas formas com o sufixo. A autora chama a atenção também para a presença de -airo, como uma variante característica do período e que, mais tarde, voltou à forma mais etimológica. Quanto aos aspectos formais, a autora considera que as bases das palavras derivadas com o sufixo são substantivos, adjetivos e preposições. A respeito dos significados, em Soledade (2001), a respeito da primeira fase do período (séculos XIII e XIV), a autora destaca:

- Indivíduo que possui qualidade ou atividade relacionada a X: proprietario, boticayro, falsayro e mansionario.

- Locativo (lugar onde se guarda X): almario

- Sem significado visível: contrairo (caso em que a base é uma preposição)

Já na segunda fase (séculos XV e XVI), Soledade (2005) classifica dessa maneira:

- Ocupação, ofício, profissão relacionadas a X: cossarios e secretario.

- Formador de adjetivos: aversairos, contrairos e necessário. 


\subsection{UMA PERSPECTIVA DIACRÔNICA DE ORIENTAÇÃO GERATIVISTA}

No trabalho de Souza (2006), unem-se os conceitos básicos da Morfologia Gerativa, como propostos por Aronoff (1976) e Basílio (1980), aos pressupostos da Morfologia Diacrônica, explicada por Joseph (1998). O corpus reunido pela autora envolve jornais, revistas, dicionários e qualquer manifestação oral ou escrita em que uma palavra derivada com o sufixo se realize. São considerados também os dados de pesquisas anteriores.

Souza (2006) define sete grupos de afinidade semântica. São eles:

a. adjetivo: alfandegário, cambiário, hereditário, lendário, literário, necessário, prioritário e solidário.

b. agente circunstancial: adversário, estagiário, falsário, mesário, milionário, presidiário, universitário e voluntário.

c. agente profissional: aeroviário, bibliotecário, discotecário, empresário, ferroviário, operário e publicitário.

d. beneficiário: alugatário, comodatário, depositário, destinatário, indultário, locatário e testamentário.

e. classificador zoológico: antozoário, cnidário, entozoário, metazoário, parazoário e locustário.

f.locativo: antiquário, aquário, armário, confessionário, fraldário, minhocário, planetário e vestiário.

g. objeto: calendário, diário, dicionário, fichário, formulário, glossário, lampadário e refratário.

Desses grupos, somente o locativo é considerado produtivo pela autora, considerando a capacidade de formar novas palavras em português, além do fato de o significado locativo ser o primeiro acessado pelos falantes, ao se depararem com uma formação $X$-ário, o que é validado por trabalhos anteriores sobre o assunto. Outro ponto que merece destaque nesse trabalho é a categoria de agente circunstancial, que se diferencia da categoria de agente habitual, que muito se vê com o -eiro (fofoqueiro, farofeiro, bagunceiro). O agente circunstancial envolve situações pontuais e tem um caráter temporário mais delimitado e situacional, ao passo que o habitual envolve a noção de frequência. O mesário só o é na época das eleições, assim como o presidiário o é enquanto está preso. Diferentemente, uma pessoa bagunceira tem o hábito de fazer bagunça, de ser desorganizada, assim como faladeira é aquela pessoa que tem o hábito de sempre falar muito. 


\subsection{UMA PERSPECTIVA DIACRÔNICA SEMÂNTICO-EVOLUTIVA}

Viaro (2008), com base nas palavras derivadas em -ário encontráveis em Houaiss e Villar (2001), descreve a diacronia do sufixo, observando os significados atestados, as etimologias e as frequências de uso, comparando, muitas vezes, os resultados atestados com o que se verifica com a forma divergente - eiro. $\mathrm{O}$ autor divide a sua investigação em três partes: $d o$ português pré-literário ao português renascentista (séculos IX-XIV), do português renascentista ao português moderno (séculos XV-XVIII) e português contemporâneo (séculos XIX e XX). Os significados atestados por Viaro (2008) são detalhados nos Quadro 1, 2 e 3, seguindo as paráfrases e divisões propostas pelo autor.

Quadro 1 - O morfema -ário do português pré-literário ao português renascentista (Adaptado de Viaro, 2008, p. 2-4)

\begin{tabular}{|c|c|c|}
\hline Significado/Valor & Substantivo & Adjetivo \\
\hline diminutivo & igrejário & \\
\hline local onde há X & santuário, armário, igrejário, & \\
\hline objeto em que há muitos $\mathrm{X}$ & antifonário, breviário, questionário & \\
\hline pessoa referente a $\mathrm{X}$ & proprietário, questionário & \\
\hline preparado de $\mathrm{X}$ & eletuário & \\
\hline que (ocorre em) $\mathrm{X}$ & & calendário \\
\hline que é de $X$ & & vestiário, ordinário, tributário \\
\hline que é X (valor redundante) & & necessário, falsário \\
\hline que está $X$ & & contrário \\
\hline que está $\mathrm{X}$ & & vigário, adversário \\
\hline que recebe $X$ & & porcionário \\
\hline que vale $X$ & & denário, ternário \\
\hline que $\mathrm{X}$ todo $\mathrm{Y}$ & & aniversário (que volta todo ano) \\
\hline relativo a $\mathrm{X}$ & & salário, vestiário, \\
\hline
\end{tabular}

Sobre os dados no Quadro 1, Viaro (2008) observa que o valor relacional que o -ário, certamente, já traz do -arius latino, serve de embrião para vários significados. A depender da 
base em que se adjunge, ele pode estender o seu significado. O autor dá como exemplo o caso de questionário em relação à base questão. Inicialmente, tinha valor relacional. Nesse caso, relativo a questão. Caso se adjunja a palavra a outra que designe pessoa, a leitura será de pessoa que faz questões. Por outro lado, se a palavra for adjungida a um objeto, será um objeto em que há muitas questões, como uma prova. Esses movimentos, segundo o autor, se ajustarão com a dinâmica própria da língua. Cabe ressaltar, desse primeiro quadro, que somente $i$ grejário e porcionário são formas inovadoras do português, sendo todas as outras heranças do latim.

Quadro 2 - O morfema -ário do português renascentista ao português moderno (Adaptado de Viaro, 2008, p. 5-7)

\begin{tabular}{|l|l|l|}
\hline \multicolumn{1}{|c|}{ Significado/Valor } & \multicolumn{1}{|c|}{ Substantivo } & \multicolumn{1}{c|}{ Adjetivo } \\
\hline abstrato & seminário & \\
\hline conjunto de X & $\begin{array}{l}\text { comentário, horário, } \\
\text { mobiliário }\end{array}$ & \\
\hline lugar de onde se X & promptuário & \\
\hline objeto em que há X & $\begin{array}{l}\text { aquário, dicionário, } \\
\text { vocabulário }\end{array}$ & \\
\hline profissão & $\begin{array}{l}\text { aquário, imaginário, } \\
\text { operário }\end{array}$ & \\
\hline que age com X & voluntário \\
\hline que é de X & extraordinário, plenário \\
\hline $\begin{array}{l}\text { que está (na sequência } \\
\text { de) X }\end{array}$ & & secundário, primário \\
\hline que está em X & & sumário \\
\hline que vale X & centenário \\
\hline relativo a X & $\begin{array}{l}\text { imaginário, judiciário, veterinário, penitenciário, bancá- } \\
\text { rio, agrário, literário, horário, mobiliário, diário }\end{array}$ \\
\hline
\end{tabular}

No Quadro 2, observa-se uma maior realização do significativo primitivo relacional do sufixo e um melhor tratamento do valor profissional e o destaque para o valor abstrato de $s e$ minário. Há uma presença destacável de palavras que chegam ao português por meio do francês, que começava a se desenvolver como língua de cultismo e prestígio internacional, tal qual o inglês é hoje. A partir do Quadro 3, do português contemporâneo, essa realidade se mostra ainda mais recorrente. 
Quadro 3 - O morfema -ário no português contemporâneo (Adaptado de Viaro, 2008, p. 7-9)

\begin{tabular}{|c|c|c|}
\hline Significado/Valor & Substantivo & Adjetivo \\
\hline conjunto de $\mathrm{X}$ & $\begin{array}{l}\text { vestuário, noti- } \\
\text { ciário }\end{array}$ & \\
\hline de que se tem $X$ & & usuário \\
\hline $\begin{array}{l}\text { local onde (ocorre) } \\
\text { X }\end{array}$ & cenário & \\
\hline $\begin{array}{l}\text { pessoa a quem se } \\
X\end{array}$ & $\begin{array}{l}\text { destinatário, } \\
\text { locatário }\end{array}$ & \\
\hline pessoa que $\mathrm{X}$ & usuário & \\
\hline profissão & $\begin{array}{l}\text { monetário, em- } \\
\text { presário }\end{array}$ & \\
\hline que está $\mathrm{X}$ & & unitário, intermediário \\
\hline relativo a $\mathrm{X}$ & & $\begin{array}{l}\text { beneficiário, monetário, ferroviário, imobiliário, revolucionário, } \\
\text { sanitário, solidário, comunitário, universitário, documentário, pu- } \\
\text { blicitário, rodoviário, agropecuário }\end{array}$ \\
\hline
\end{tabular}

Em linhas gerais, o trabalho de Viaro (2008) apresenta um cauteloso tratamento evolutivo dos significados do sufixo. Com base no que o autor atestou, o detalhamento exaustivo pode ser resumido da seguinte maneira: (i) agente: empresário, operário, imaginário, questionário, proprietário; (ii) objeto: antifonário, breviário, dicionário, vocabulário, aquário; (iii) local: cenário, santuário, armário, igrejário; (iv) coletivo: comentário, horário, mobiliário, vestuário, noticiário; e (v) adjetivo relacional: imaginário, judiciário, penitenciário, agrário, literário, horário, mobiliário, diário, monetário, ferroviário, imobiliário, revolucionário, solidário, comunitário, universitário, documentário, publicitário, rodoviário, agropecuário.

\section{CONSTITUIÇÃO DE CORPUS: COLETA, METOdOLOGIA E ANÁLISE}




\subsection{METODOLOGIA}

Os dados de investigação desta pesquisa foram coletados em todo o site do Corpus Informatizado do Português Medieval ${ }^{3}$, constando todos os textos entre os séculos XIII e XVI. Ao total, foram encontradas 4834 palavras terminadas em -ário, -airo e-eiro. Para o trabalho que aqui se desenvolve, foram excluídas as formas em -eiro, considerando que esse, embora de um mesmo étimo, é um morfema divergente, com o qual o -ário nem sempre estabelece uma relação próxima, a ponto de os falantes atuais não interpretarem como uma variação fônica de um mesmo afixo. Diferentemente, a forma - airo foi mantida, considerando que seja um alomorfe que sofre um pequeno processo fonológico (metátese) e que não impede de relacioná-lo com o -ário, tendo em vista que, no português arcaico, são encontráveis as chamadas formas duplas, como vicário e vicairo, certamente em função de não existir ainda uma normatização linguística. Além disso, as gramáticas históricas mostram que as formas em -airo do período voltaram a -ário, por influência da linguagem culta.

As medidas aqui tomadas se pautam também nas visões de Booij (2014) acerca da aceitabilidade da alomorfia quando essa não impedir relações morfolexicais. X-ário e X-airo são, então, tratadas como variações de uma mesma construção. Excetuadas as formas $X$-eiro, o corpus passa a compreender 514 realizações de $X$-ário e $X$-airo, mas isso não quer que sejam 514 palavras diferentes. Desconsideradas as repetições, são atestadas apenas 58 instanciações distintas do esquema $\left[\mathrm{X}_{\mathrm{i}} \text {-ário }\right]_{\mathrm{Nj}}$.

Num segundo momento, foi feita uma consulta lexicográfica, o que inclui a pesquisa etimológica, para 1) atestar se a palavra é realmente sufixada ou apenas terminada ${ }^{4}$ em forma fonológica equivalente ao sufixo; 2) verificar se é herança latina ou criação do português arcaico e, 3) fornecer pistas acerca do significado, que não pode ser atestado, valendo-se exclusivamente de dicionários da língua contemporânea. As obras consultadas foram:

(i) etimológicos, como o Dicionário Etimológico da Língua Portuguesa (2007), de Antônio Geraldo da Cunha;

(ii) históricos acerca do período arcaico, como são o Dicionário da Língua Portuguesa Arcaica (2005), de Zenóbia Collares Moreira, o Dicionário Etimológico do Portu-

3 Disponível em: <cipm.fcsh.unl.pt>. Acesso em: 05 set 2015.

4 Exemplos para esse problema são os casos de cadeira e macaxeira, palavras terminadas em -eir-, mas onde a sequência fônica não é um morfema e sim partes das raízes dessas palavras, como pode ser atestado numa consulta etimológica. Para mais informações, ver Viaro, Ferreira e Guimarães Filho (2014). 
guês Arcaico (2013) e o Pequeno Vocabulário do Português Arcaico (2014), ambos de Américo Venâncio Lopes Machado Filho e o Dicionario de dicionarios do galego medieval, obra disponibilizada via web e coordenada por Ernesto González Seoane, María Álvarez de la Granja e Ana Isabel Boullón Agrelo, entre os anos de 2006 e 2012;

(iii) antigos, como o Vocabulario portuguez e latino, de Raphael Bluteau (1728) $)^{5}$, o Diccionario de lingua portugueza, de Antonio de Moraes Silva (1789) ${ }^{6}$, o Diccionario da Lingua Brasileira, de Luiz Maria da Silva Pinto (1832) ${ }^{7}$ e o Elucidário das palavras, termos e frases que em Portugal antigamente se usaram e que hoje regularmente se ignoram, de Joaquim de Santa Rosa de Viterbo (1865) ${ }^{8}$;

(iv) modernos, como o Dicionário Houaiss de Língua Portuguesa, de Antônio Houaiss e Mauro Villar (2001) e o Dicionário Online Caldas Aulete ${ }^{9}$, ambos utilizados em último recurso e com muita ressalva.

\subsection{ANÁLISE}

Como dito anteriormente, os dados levantados no corpus selecionado ofereceram um total de 514 realizações de $X$-ário e $X$-airo, que, desconsideradas as repetições, representam 58 instanciações distintas do esquema $\left[\mathrm{X}_{\mathrm{i}} \text {-ário }\right]_{\mathrm{Rj}}$. Partindo da consideração de Viaro (2008) de que o valor relacional, herança do -arius latino, serve de embrião para vários significados do sufixo -ário, desconstruímos a tese de extensão de sentido polissêmico cujo percurso tenderia a ir do sentido mais concreto para o mais abstrato, que está na base tanto da teoria da gramaticalização, cujo percurso unidirecional aponta a trajetória do lexical para o gramatical, quanto da teoria da metáfora conceitual, dada a cadeia monodirecional causal que partiria da experiência sensório-motor, levando a esquemas imagéticos, desses esquemas imagéticos a conceitos abstratos e deles a expressões linguísticas.

\footnotetext{
Disponível em < http://www.brasiliana.usp. br/pt-br/dicionario/edicao/1>. Acesso em 08 mar 2015. Disponível em < http://www.brasiliana.usp. br/pt-br/dicionario/edicao/2>. Acesso em 08 mar 2015. Disponível em < http://www.brasiliana.usp. br/pt-br/dicionario/edicao/3>. Acesso em 08 mar 2015. Disponível em < http://purl.pt/13944>. Acesso em 08 mar 2015.

Disponível em < http://www.aulete.com.br/>. Acesso em 08 mar 2015.
} 
Ao que parece, os empregos de -ário como adjetivos ocupam um lugar de centralidade na expansão dos sentidos polissêmicos do esquema de construção a partir desse elemento formativo e tem implicações diretas acerca da formulação do esquema dominante, uma vez que, como foi discutido na seção 2.1, a descrição de padrões que implicam a flutuação categorial entre substantivos e adjetivos requer, em português, a adequação do modelo proposto por Booij (2010), relativizando o caráter absoluto da propriedade esquemática identificada como a categoria do output.

Assim, a análise dos dados indica que o esquema dominante, para as construções em ário no português arcaico, implica na não explicitação de categorias morfossintáticas, nem para os produtos (que flutuam entre adjetivos e substantivos), nem para as bases (inputs que são variados conforme irá ser demonstrado na análise de subesquemas a seguir). Desse modo, propõe-se um esquema dominante, sem marcas morfossintáticas e de caráter semântico geral, para que possa abrigar as variedades de sentido que os subesquemas irão produzir:

$$
<\left[\mathrm{X}_{\mathrm{i}}-\text { ário }\right]_{\mathrm{Rj}} \leftrightarrow\left[x \text { envolvido em } \mathrm{SEM}_{\mathrm{i}}\right]_{\mathrm{Rj}}>
$$

As instanciações de valor relacional representam 18 das 58 ocorrências (arbitraria, extra-ordenario $\sim$ extraordinário, hereditária, hordenairos $\sim$ ordinários, ĩcẽdiario, involuntárias, leigario $\sim$ leigaryo, mundairas $\sim$ mumdayras, caluario, necesaria $\sim$ necessário, penitenciario, reliquairo, segundario $\sim$ segundarios, selario, solitaria $\sim$ solitário, temerário, ternário, voluntario). Em algumas delas, o emprego como modificador (MOD) pode causar estranhamento ao falante atual, uma vez que são formas usualmente empregadas como núcleos de sintagmas nominais (NSN), como por exemplo, calvário, que aparece como modificador de monte e reliquairo (relicário) que ocorre como modificador de samto, apresentando o sentido de 'precioso, de grande valor'. Essas ocorrências, no entanto, reforçam o caráter central das instanciações relacionais que, por sua vez, já apresentam embriões de outras noções que irão integrar a rede polissêmica desse formativo, por exemplo, o valor agentivo já se pode antever em instanciações como ternário ('que herda a terça parte') e voluntário ('que não age por obrigação'), ou ainda a noção de quantidade embutida em selário ('quantia/taxa paga pelo selo’), ou por exemplo, o valor locativo que já se antecipa em solitária (çella solitaria).

Nesse subesquema, a noção relacional tem implicação direta sobre o comportamento morfossintático e vice-versa, assim, a representação formal contará com a especificação da categoria do output como A (adjetiva), contudo, a categoria das bases (inputs) deverá ser omitida, uma vez que constam como bases: verbos, substantivos, preposições e numerais. 
$<\left[\mathrm{X}_{\mathrm{i}}-\text { ário }\right]_{\mathrm{Aj}} \leftrightarrow\left[\text { qualidade relativa a } \mathrm{SEM}_{\mathrm{i}}\right]_{\mathrm{Aj}}$

As instanciações de um subesquema agentivo também se revelaram bastante produtivas nos dados analisados, contabilizando um total de 23 palavras (adversario $\sim$ adversairo $\sim a$ versario $\sim$ averssairo, ceroferario, comendatário, compromisario, correlarios, domaayros, falsario $\sim$ falsayro, hostiário, hüguentayro, notario $\sim$ notayro, prisioneiros, proprietário, secretairo $\sim$ secretario, solicitario, terçenairo, uestiayro $\sim$ vistiario, vicayro $\sim$ vigayro, vsufructuarya, cõcubinario $\sim$ concobinario $\sim$ concubinário, ordenaria $\sim$ ordinayro $\sim$ ordinário, trebutarios $\sim$ tributário, vsorario $\sim$ vsurario, boticairos $\sim$ buticayro). Há que se considerar, contudo, aspectos variantes entre os tipos de agentes, pois podemos encontrar uma natureza agentiva que implica uma habitualidade em relação aquilo que se pratica (p. ex.: falsário, usurário, tributário), bem como um caráter eventual/circunstancial da agentividade (p. ex.: prisionairo, proprietário), por sua vez, instanciações desses subesquemas ainda podem apresentar uma noção de agente beneficiário (p. ex.: usufrutuário, tercenário) ou ainda de um agente profissional (p. ex.: boticário, corsário, vestiário, vigairo, domaayro, notário, ostiário, ceroferário).

Acerca do caráter profissional dos agentivos é importante ressaltar a sua estreita relação com os agentes habituais. Soledade (2015), acerca dos agentes produzidos pelo esquema do sufixo -dor, explica que qualquer agente habitual, em tese, pode ser recategorizado como agente profissional, é uma questão de conceptualização que depende do uso, da necessidade expressiva dos indivíduos, das relações interacionais e socioculturais dos agentivos em dada comunidade linguística, e que essa conceptualização em nada dependente das relações de herança da base.

A distinção entre agente habitual e agente profissional parece residir no fato de que todo agente profissional habitualmente pratica a ação expressa pelo verbo, contudo, dessa prática decorrem pelo menos dois comportamentos socioculturais que o especificam, a saber: 1) o retorno financeiro a fim de subsistência e 2) o acúmulo de conhecimento ou de prática específica para o exercício da ação.

Portanto, a relação polissêmica que se dá entre os agentes habituais e os profissionais parece ser de natureza metonímica, sendo uma relação entre parte-todo, ou ainda de continente-conteúdo. 
Da mesma forma, agentes beneficiários parecem ser uma subcategorização de agentes eventuais/circunstanciais, uma vez que não implica num estado ou numa habitualidade, mas sim em uma situação decorrente de um contexto circunstancial, pontual.

Assim, segundo o modelo construcional de Booij (2010), uma possível representação dessa rede polissêmica em torno da noção de agente poderia ser formulada como a seguir:

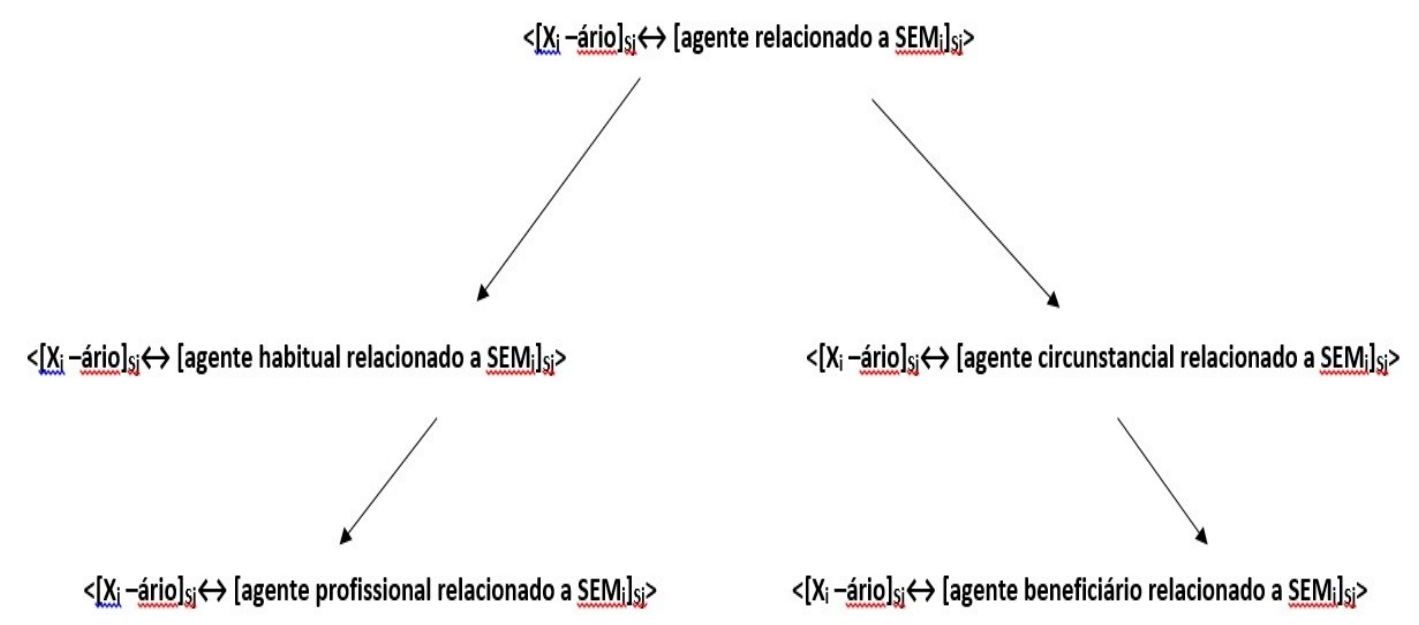

Observe-se que a categoria do input foi omitida, enquanto se especifica a categoria do output como substantiva.

Há ainda, nos dados analisados, 14 instanciações que podem ser descritas como objetos (antifanario, bribiario, calandairo $\sim$ kallemdairo, capitulayro, cartairos $\sim$ cartarios, ẽuentayro $\sim$ jnuentario, lycionayro, octauayros $\sim$ octauairos, rosairo, sodayro $\sim$ ssudayro, penentençiairo $\sim$ penitenciários, ssumayro $\sim$ sumario), ainda que algumas apresentem um caráter fronteiriço entre objeto e lugar (almario, cossairo corsário).

Propor uma rede de subesquemas para a categoria objeto é tarefa bem complexa, uma vez que, como se observa nas reflexões de Viaro (2008) expostas nos quadros 1, 2 e 3 na seção 3.4, as bases têm um papel preponderante sobre os sentidos das instanciações desse subesquema, assim temos objetos que se apresentam com a noção 'resultado de processo', como inventário; objetos que são 'instrumentos de uso' como sudário, objetos que se apresentam com a noção 'conjunto' como capitulário, e ainda, aqueles já destacados, que se apresentam na fronteira entre objeto e local. Assim, na descrição desses dados, não se buscará a descrição 
dos subesquemas de objeto, que será representado com a categoria do produto como substantivo e a categoria da base não especificada, uma vez que se verificam verbos e substantivos como outputs possíveis de serem compatibilizados a esse esquema.

$$
<\left[\mathrm{X}_{\mathrm{i}}-\text { ário }\right]_{\mathrm{Sj}} \leftrightarrow\left[\text { objeto relacionado a } \mathrm{SEM}_{\mathrm{i}}\right]_{\mathrm{Sj}}
$$

As instanciações em -ário ainda apresentaram no português arcaico a possibilidade de realizarem a noção de local, revelando-se em 5 palavras distintas (campanairo, fossario, sacrario $\sim$ sagrario, santuario $\sim$ santuários, solayro $\sim$ solairo $)$. Assim, como o esquema de objeto, os locativos, em geral, também podem apresentar uma polissemia produtiva, por exemplo: 'lugar onde existe grande quantidade da base', 'lugar onde existe a base', 'lugar onde se pratica uma atividade relacionada a base' e ainda 'local relacionado a base'. Nos exemplos encontrados podemos verificar, três sentidos distintos: 1) em fossário 'onde existem muitos fossos, cemitério' e sacrário 'onde se guardam os objetos sagrados', tem-se o valor descrito como 'lugar onde existe grande quantidade da base'; 2) em campanário 'torre da igreja onde fica o sino (campana)', tem-se a noção de 'lugar onde existe a base' e 3) em santuário 'altar, lugar sagrado' e solário 'terraço sobre as casas, parte mais exposta ao sol', identifica-se a noção de 'local relacionado a base'. Pode-se, contudo, entender que esses sentidos estão relacionados entre si, num crescendo de especificação, i.e., existe uma relação de conteúdocontentor:

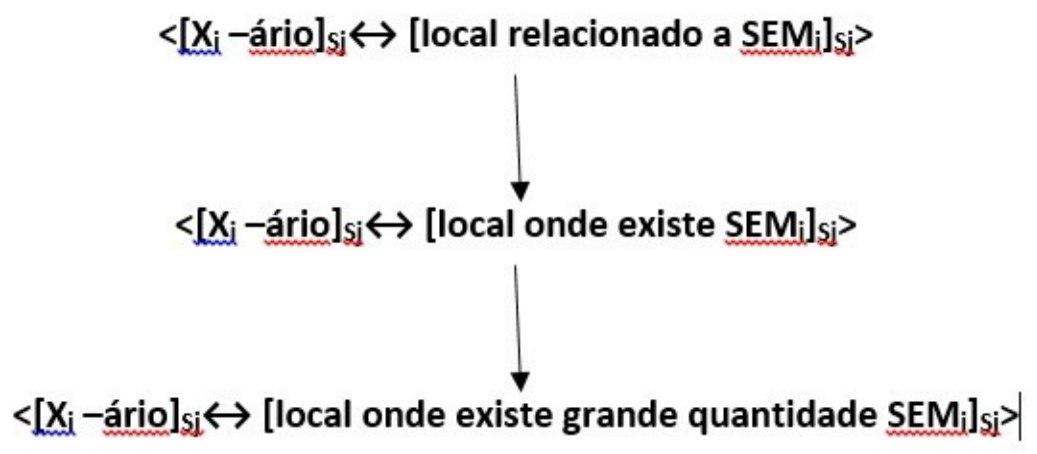

Novamente, a categoria da base deve ser omitida, uma vez que adjetivos e substantivos se apresentam como inputs para as instanciações do esquema locativo, já a categoria do produto pode ser especificada como substantiva.

Em síntese, considerando o esquema dominante e os subesquemas mais gerais, segundo a proposta da morfologia construcional de Booij (2010), as formações em -ário, nos dados do português arcaico, podem ser representadas na esquematização: 


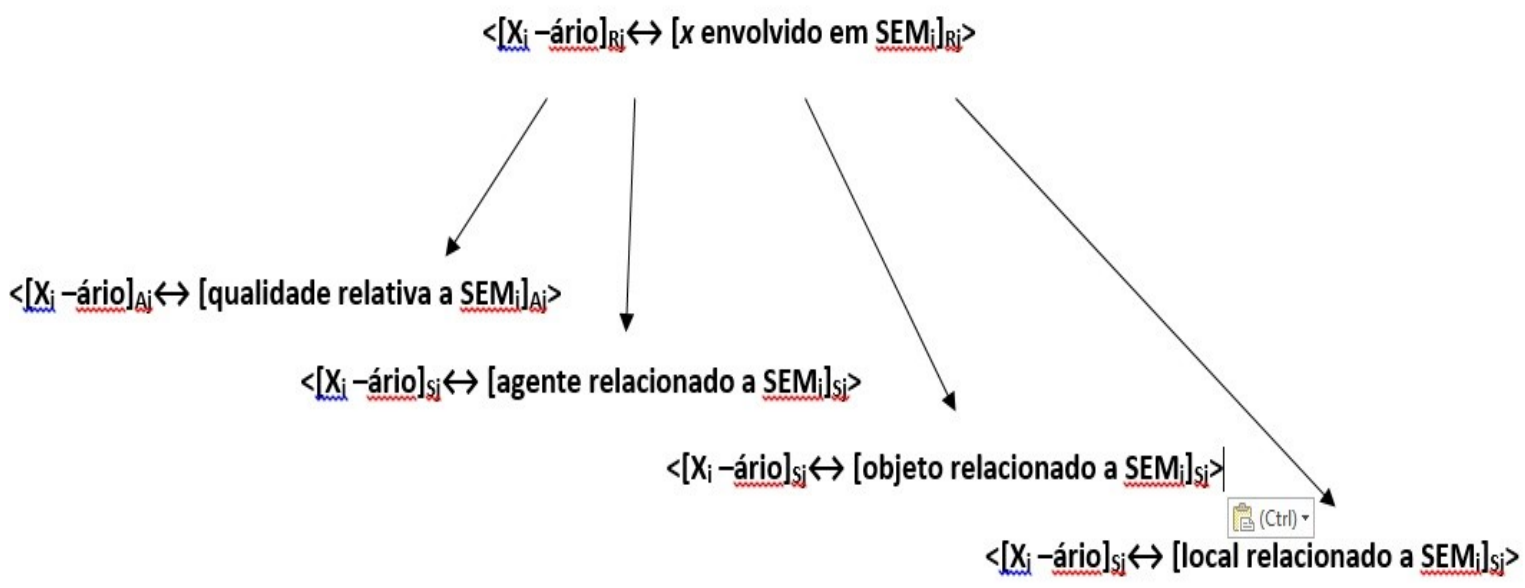

Note-se, contudo, nesse modelo de representação a dificuldade de se inserirem os subesquemas que refletem a polissemia de subsesquemas como os de agente e local. Além disso, aspectos como produtividade, prototipicidade e herança semântica da base também não estão contemplados.

\section{CONSIDERAÇÕES FINAIS}

Diante do exposto, é importante considerar que, no modelo proposto por Booij (2010, 2012, 2014), há ainda um forte apego a métodos de representação usuais dentro do modelo gerativista, bem como, uma preocupação, ainda incipiente, de descrição da contribuição semântica para os processos de construção morfológicos.

Ressalte-se, contudo, que morfologia construcional de Booij (2010) oferece fundamentos essenciais para a compreensão da estruturação do léxico em termos de construção e esquemas; embora careça de adaptações, uma vez que ainda não se mostra eficiente no tratamento de aspectos importantes, levantados nas análises aqui desenvolvidas, como flutuação categorial do constructo e, sobretudo, das mais variadas relações semânticas que demandam especificação, como as que se dão entre bases e palavras complexas, entre esquemas e palavras complexas, entre esquemas e subesquemas, entre subesquemas e subesquemas.

\section{REFERÊNCIAS}

ALI, Said. Gramática histórica da língua portuguesa. 7 ed. São Paulo: Melhoramentos, 1964. 
ARONOFF, Mark. Word formation in gerative grammar. Cambridge: The MIT Press, 1976.

BASÍILIO, Margarida. Re-estudo de agentivos. Comunicação apresentada no VI Encontro Nacional de Linguistica. Rio de Janeiro: PUC-RJ, 1981.

BASÍLIO, Margarida. Abordagem gerativa e abordagem cognitiva na formação de palavras: considerações preliminares. In: Linguística, v. 5, n. 2, p. 01-14, dez. 2010.

BASÍLIO, Margarida. Estruturas lexicais do português: uma abordagem gerativa. Petrópolis: Vozes, 1980.

BASÍLIO, Margarida. O fator semântico na fluidez substantivo/adjetivo em português. IN: HEYE, Jürgen (Org.). Flores verbais. Rio de Janeiro: 34/Nova Fronteira, 1995, p. 177-192.

BASÍLIO, Margarida. O papel da metonímia na morfologia lexical. In: Revista Virtual de Estudos da Linguagem, v. 9, p. 99-117, 2011.

BOOIJ, Geert . Morphology in Construction Grammar [to appear in Thomas Hoffmann and Graeme Trousdale (Ed.). The Oxford Handbook of Construction Grammar. Oxford: Oxford University Press, 2012].

BOOIJ, Geert. Construction Morphology. Oxford: Oxford University Press, 2010.

BOOIJ, Geert. Inheritance and motivation in Construction Morphology. In: GISBORNE, Nikolas; HIPPISLEY, Andrew. (Eds.). Defaults in morphological theory. Oxford: Oxford University Press. [to appear]. Disponível em: <

https://geertbooij.files.wordpress.com/2014/02/booij-2015-inheritance-issues-in-constructionmorphology-feb-2014.pdf>. Acesso em: 23 set 2015.

BOTELHO, Laura Silva. Uma abordagem sociocognitiva das construções agentivas em Xeiro. In: MIRANDA, N. S.; SALOMÃO, M. M. (Org.). Construções do português do Brasil: da gramática ao discurso. Belo Horizonte: Editora UFMG, 2009, p. 178-201.

CÂMARA JR., Joaquim Mattoso. Estrutura da língua portuguesa. 15. ed. Petrópolis: Vozes, 1970.

CÂMARA JR., Joaquim Mattoso. História e estrutura da língua portuguesa. 15. ed. Rio de Janeiro: Padrão Livraria Editora, 1975.

CASTILHO, A. Nova gramática do português brasileiro. São Paulo: Contexto, 2010.

CUNHA, A. G. Dicionário etimológico da língua portuguesa. 3. ed. Rio de Janeiro: Lexikon Editora Digital, 2007.

ELSON, B.; PICKETT, V. Introdução à Morfologia e à Sintaxe. Tradução de Aryon D. Rodrigues e outros. Petrópolis: Vozes, 1973.

GOLDBERG, Adele. Constructions: a construction Grammar approach to argument structure. Chicago: The University of Chicago Press, 1995 
GONÇALVES, Carlos Alexandre Victorino; ALMEIDA, Maria Lucia Leitão de. Morfologia Construcional: principais ideias, aplicação ao português e extensões necessárias. Alfa. São Paulo, 58 (1), 2013. p. 165-193.

HOUAISS, Antonio; VILLAR, Mauro de Salles. Dicionário Houaiss da Língua Portuguesa. Rio de Janeiro: Objetiva, 2001.

JACKENDOFF, Ray. Morphological and Semantic Regularities in the Lexicon. In: Language 51, 1975, p. 639-71.

JACKENDOFF, Ray. What is the human language faculty? Two views. Language 87.2011, p. 586-624.

JOSEPH, B. Diachonic Morphology. In: SPENCER, A.; ZWICKY, A. (eds.). The Handbook of Morphology. Londres: Basil Blackwell, 1998.

LOBATO, Lúcia. Sintaxe gerativa do português: da teoria padrão à teoria da regência e ligação. Belo Horizonte: Vigília, 1986.

LOPES, Mailson dos Santos. A prefixação na primeira fase do português arcaico: descrição e estudo semântico-morfolexical-etimológico do paradigma prefixal da língua portuguesa nos séculos XII, XIII e XIV. 2013. 943p. Dissertação (Mestrado em Letras e Linguística) — Instituto de Letras, Universidade Federal da Bahia, Salvador.

MACHADO FILHO, Américo Venâncio Lopes. Dicionário etimológico do português arcaico. Salvador: Edufba, 2013. 536p.

MACHADO FILHO, Américo Venâncio Lopes. Pequeno Vocabulário do Português Arcaico. Brasília: Editora UnB, 2014. 520p.

MARINHO, Marco Antonio Ferreira. Questões acerca das formações X-eiro do português do Brasil. 2004. Dissertação de Mestrado em Língua Portuguesa. Rio de Janeiro: UFRJ/Faculdade de Letras.

MOREIRA, Zenóbia. Dicionário da língua portuguesa arcaica. Natal: EDUFRN. 2005. 574p.

NUNES, José Joaquim. Compêndio de gramática histórica portuguesa. Lisboa: Livraria Clássica Editora, 1969.

PERINI, Mário. Gramática descritiva do português. São Paulo: Editora Ática,1995.

RIO-TORTO, Graça Maria. Desafios em morfologia: história e (re)conhecimento. In: VIARO, Mário Eduardo (Org.). Morfologia histórica. São Paulo: Cortez Editora, 2014, p. 31-57.

SOLEDADE, J. Experimentando esquemas: um olhar sobre a polissemia das formações [[X

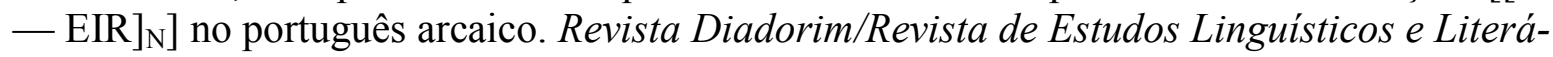
rios do Programa de Pós-Graduação em Letras da Universidade Federal do Rio de Janeiro. Rio de Janeiro, número especial, 2013. p. 83-111.

SOLEDADE, Juliana. Aspectos morfolexicais do português arcaico: sufixação nos séculos XIII e XIV. 2001.2 v. 400 p. Dissertação de mestrado (Mestrado em Letras e Linguística) Instituto de Letras, Universidade Federal da Bahia, Salvador. 
SOLEDADE, Juliana. De pecadores a sabedores: agentes de -dor no Livro das Aves. (Comunicação Pessoal) I congresso internacional de semântica cognitiva, Salvador, 2015.

SOLEDADE, Juliana. Semântica morfolexical: contribuições para a descrição do paradigma sufixal do português arcaico. 2005. 2v. 575 p. Tese (Doutorado em Letras e Linguística) Instituto de Letras, Universidade Federal da Bahia, Salvador.

SOUZA, Mariana Pereira. Formações X-ário no português do Brasil: um estudo sobre a produtividade lexical. 2001. Dissertação de Mestrado em Língua Portuguesa. Rio de Janeiro: Faculdade de Letras (Universidade Federal do Rio de Janeiro).

VALENZUELA, Javier; IBARRETXE-ANTUÑANO, Iraide; HILFERTY, Joseph. La Semántica Cognitiva. In: IBARRETXE-ANTUÑANO, Iraide; VALENZUELA, Javier. (Ed.). Lingüística Cognitiva. Barcelona: Anthropos, 2012, p. 34-60.

VIARO, Mário Eduardo. Os sufixos -eiro e -ário: história de morfemas divergentes. In: Anais do I Simpósio Mundial de Estudo de Língua Portuguesa - SIMELP. São Paulo: Simpósio Mundial de Estudo de Língua Portuguesa - SIMELP, 2008.

VIARO, Mário Eduardo. Problemas de morfologia e semântica histórica do sufixo -eiro. Estudos Linguísticos. São Paulo, v. 35, 2006, p. 1443-1452.

VIARO, Mário Eduardo; FERREIRA, Michael; GUIMARÃES FILHO, Zwinglio. Derivação ou terminação: limites para a semântica, lexicologia e morfologia históricas. In: VIARO, Mário Eduardo (Org.). Morfologia histórica. São Paulo: Cortez Editora, 2014, p. 58-105.

Recebido em 12 de março de 2015.

Aceito em 13 de maio de 2015. 
